\title{
EL IMPACTO DE LA VARIABLE DE GÉNERO EN LA MIGRACIÓN Honduras-MÉXico: el CASO de las Hondureñas en Frontera COMALAPA
}

\author{
Nicanor Madueño Haon
}

Resumen:Este artículo se basaen dos estudios de camporealizados en Frontera Comalapa en agosto de 2008 y abril de 2009. Pretende participar en la inclusión de variables de género y de etnificación al análisis de las trayectorias migratorias. Se concluye que la migración femenina no genera cambios sustanciales en las relaciones de dominación que pueden existir en el país de origen. Al contrario, esas relaciones se acentúan durante la migración y se imponen como base de lasestrategias de sobrevivencia o de evolución en el país de llegada.

Palabras clave: migración, género, frontera, relaciones laborales, maquiladoras, registro civil, salud, educación

Enviado a dictamen: 25 de abril de 2010 Aprobación: 10 de noviembre de 2010

Revisiones: 1

Nicanor Madueño Haon, Maestro en Ciencia Política, Institut d'Études Politiques de Paris. Correo electrónico: nicanorhaon@gmail.com.
Abstract: This article is based on two field studies in August 2008 and April 2009 in the municipality of Frontera Comalapa. It intends to participate to the inclusion of gender as a structuring element in migration studies. It is concluded that women migrations don't necessarily question power relations that may exist in the country of departure. On the contrary, these relations rather increase during migration and impose themselves as basis of survival or evolution strategies in the country of arrival.

Keywords: gender, migration, border, gender division of labour, maquiladoras, vital records, health, education

\section{Introducción}

$\mathrm{F}$ rontera Comalapa es el lugar histórico de un mosaico de migraciones. Creado en 1921 después del establecimiento de la frontera con Guatemala a finales del siglo XIX, el municipio prosperó principalmente gracias a la agricultura que se desarrolló en vínculo con Guatemala, a través de la movilidad de los propietarios y de los propios trabajadores agrícolas. Hoy todavía flujos de trabajadores temporales llegan al municipio desde Huehuetenango y los departamentos colindantes durante el período de cosecha del café. La historia de Frontera Comalapa también fue marcada por la llegada de muchos guatemaltecos que huían 
de la violencia del conflicto civil en la década de los ochenta, y por la instalación de un campo de refugiados en el municipio. Empezada por parte bajo la impulsión de refugiados y ex refugiados centroamericanos, la emigración hacia Estados Unidos se amplificó durante los noventa con la explosión de las migraciones de paso. Por su situación de intersección entre la carretera panamericana y la frontera con Guatemala, el municipio de Frontera Comalapa se encuentra en una de las rutas migratorias que atraviesan el estado de Chiapas, entre, por una parte, el itinerario dicho de "selva" que pasa por el norte del estado, y por otra parte el corredor costeño que se extiende desde Tapachula hasta Arriaga. La prosperidad de la ciudad, en comparación con los municipios colindantes, hace de Frontera Comalapa una etapa para los migrantes que desean ahorrar dinero con el fin de continuar su ruta hacia Estados Unidos. Además, el municipio se ubica cerca de varios puntos de paso clandestino desde Guatemala, mientras que el tránsito oficial es libre entre las ciudades fronterizas de Cd. Cuauhtémoc - municipio de Frontera Comalapaen México y La Mesilla en Guatemala.

La presencia hondureña en Frontera Comalapa toma sus raíces en el flujo de paso inicialmente dirigido a Estados Unidos. A partir de la segunda mitad de los noventa, la emigración hondureña femenina aumentó mientras que la situación laboral en Estados Unidos se volvía cada vez más difícil y que el cruce de México iba volviéndose aún más peligroso (Ruiz, 2003). Llegando solas, bien sea por accidente, voluntariamente o abandonadas por sus polleros, muchas de esas mujeres han convertido lo que se suponía un paso por esa ciudad en una estancia de varios años. Esa situación puede explicarse por las posibilidades de encontrar ingresos, por el inicio de una vida conyugal y también por una posibilidad de visitar familiares en Honduras más fácilmente que desde Estados Unidos. Si para algunas la intención de quedarse en Frontera Comalapa es clara, la mayoría sigue viviendo en un "destino no planeado" (Fernández, 2009).

\section{La migración hondureña: \\ tendencia global y presencia en Chiapas}

La migración hondureña es emblemática de la tendencia mundial al aumento de los flujos de migración femenina y más precisamente de los flujos de mujeres que emigran solas. La parte de mujeres en la emigración tomó proporciones abrumadoras en países como Filipinas, Sri Lanka, Indonesia o Cabo Verde. En el año 2005, representaron en estos países, respectivamente, más de $60 \%$ - para los dos primeros-, $80 \%$ y $85 \%$. Si nos acercamos a Honduras, la proporción de mujeres entre los migrantes internacionales aumentó de 40\% a 50\% en América Latina y el Caribe entre 1960 y 2005 (Simon, 2008).

En cuanto a la emigración desde Honduras, los datos son muy difíciles de establecer, y más aún los de la migración femenina. Sin embargo, podemos recoger algunas informaciones que podrían alimentar la suposición de su tendencia a la feminización y su aumento en términos generales desde 1998. De hecho, las primeras olas de gran emigración hondureña se dieron en este último año, causadas por el huracán Mitch y la agudización de la crisis del plátano. La ausencia de conflicto civil abierto y de emigración de refugio hace de la emigración hondureña en México la más reciente entre las poblaciones centroamericanas.

En Estados Unidos de América, la proporción de mujeres entre los migrantes hondureños que cuentan con permiso de estancia sigue siendo alrededor de 53\% entre 1980 y 1990 (Baeza, 2008). Se constata, pues, una ligera mayoría de mujeres, y se puede suponer que la proporción de mujeres en el total de migrantes hondureños es mucho mayor. Eso debido al hecho de que la regularización se supone más difícil para las mujeres y que el número de mujeres deportadas a Honduras ha crecido entre 2001 y 2007 de $7 \%$ a 11,4\% del total de deportados (Foro Nacional para las Migraciones en Honduras, 2008).

En México, serian 3,941 las personas residentes en el país que nacieron en Honduras, es decir 0,8\% 
del total de personas nacidas en el extranjero. Por lo menos 56\% de estas serían mujeres (INEGI, 2007). ${ }^{1}$ Sin embargo, esta cifra solo toma en cuenta las personas que se declaran nacidas en Honduras, mientras que muchas de ellas tienden a ocultar su país de nacimiento debido a su situación de irregular. En Chiapas, la oficina de INM en Tapachula emitió 1,139 FM32 entre enero de 2006 y julio de 2008, incluidos 316, 27,8\%, a hondureños. Según esa misma oficina, $61 \%$ de todos los FM3 fue emitido para mujeres (Fernández, 2009). Esta cifra está muy por debajo de la realidad de la presencia hondureña en el estado, que puede estimarse en $90 \%$ en situación irregular (Fernandez, 2009). Aunque los datos cruzando las variables de sexo y nacionalidad no están disponibles, las observaciones de campo en Frontera Comalapa y al consulado de Honduras en Tapachula dejan pensar que la gran mayoría de los hondureños establecidos en Chiapas son mujeres.

\section{El desafio del estudio cualitativo de las migraciones femeninas}

Los estudios de las migraciones han sido durante mucho tiempo realizados como si en éstas sólo participaran los hombres (Cruzy Luz, 2007; Kauffer, 2008). Eso ocultó por un tiempo el hecho de que el género es un determinante importante de los recursos disponibles y utilizables por los migrantes, así como de los procesos que se aplican a los individuos y sus oportunidades para establecer lazos sociales. Se trata de un elemento estructural de las causas de la migración, de la construcción de rutas migratorias y de las decisiones adoptadas durante la misma. El interés de un estudio tomando en cuenta las relaciones de género, más allá de un mero estudio "sobre las mujeres" es contribuir a la comprensión de la migración en su complejidad.

Entendemos aquí como "género" el concepto que identifica la construcción social y cultural de la diferencia de sexo, lo que implica relaciones de poder y dominación. Lo utilizamos en contra de la concepción que atribuye naturalidad al comportamiento de los hombres y mujeres. Esto, para poner en relieve que las relaciones de poder y dominación de las cuales son objeto las mujeres existen sobre la base de construcciones culturales y sociales y no sobre dichos elementos "naturales". El género es un concepto dinámico que se articula a la edad, la etnicidad y la condición socioeconómica. Es estructural en la migración, ya que define la posición social en el país de partida "papel en la familia", falta de ingresos, libertad o no de movimiento, estigmas como el del divorcio o del sexo extramatrimonial etcétera, y las posibilidades de evolución en el lugar de llegada "empleo, oportunidades para estrategias matrimoniales, ambos impactando sobre las posibilidades de regularización administrativa, etcétera". Los mecanismos de género también pueden ser utilizados por los migrantes para la movilización de recursos "alta demanda de mano de obra en sectores como el trabajo doméstico o las maquiladoras, uso de la imagen materna para evitar controles migratorios, uso del sexo como moneda de cambio, etcétera" o para establecer lazos sociales.

Mirjana Morokvasic (2007) destacó la importancia de no considerar a los migrantes como perpetuos objetos de cambio, sino como agentes de cambio a través de la migración. El análisis de esta autora se centra en el hecho de que la migración no invalida necesariamente las barreras erigidas por el orden de géneros, aunque las migrantes pueden instrumentalizar estas barreras para defender sus intereses:

El orden de género no es necesariamente afectado por la migración femenina, al contrario, existe mucha evidencia empírica de que este orden es significativamente resistente a los cambios asociados con la migración que participan, incluso en el caso de intercambio de los papeles tradicionales [del hombre y la mujer]. [...] Yo iría más allá de la simple pregunta de si las relaciones de género se reconfiguran en el contexto de la migración. Quería preguntar cómo se negocian las implicaciones y qué lugar se puede 
encontrar para la agencia, la adquisición de más autonomía y la toma de más poder de decisión. Eso me parece fundamental, si uno se inscribe en una perspectiva que considera los migrantes como actores de cambio y no como objetos de cambio. El punto principal de mi argumentación es que los migrantes tienden a utilizar [...] el orden tradicional de los géneros con el fin de alcanzar sus objetivos si no lo impugnan o lo ponen en duda (Morokvasic, 2007).

Nuestra hipótesis es que aun cuando la emigración puede hacer que las migrantes ganen en autonomía y en poder de decisión, las relaciones de dominación que existen en el país de partida se reproducen en el país de llegada. Por lo contrario estas relaciones de dominación pueden ser reforzadas por la situación de extranjera, de irregular, o utilizadas a través de estrategias varias.

\section{El género, elemento estructurante del movimiento migratorio Honduras-Chiapas}

\section{San Pedro Sula, Honduras, principal región de partida de las hondureñas establecidas en Frontera Comalapa}

San Pedro Sula es la principal región de partida de las hondureñas que se encuentran hoy en Frontera Comalapa. La ciudad de San Pedro Sula es la capital económica de Honduras. Se encuentra en el Valle de Sula, una región que ha prosperado de manera independiente del resto del país. Eso debido a dos factores de desarrollo económico: el cultivo y la exportación de plátano, y luego la instalación de maquiladoras. También es la región hondureña más poblada, con más de un millón de habitantes y tiene con la región de Tegucigalpa el Índice de Desarrollo Humano, IDH, más alto del país "superior a 0,78". También tiene una situación costera en la frontera con Guatemala, lo que hace de ella un cruce entre las rutas migratorias y comerciales que vinculan América Central, Caribe y Estados Unidos de América.
San Pedro Sula despegó económicamente en la segunda mitad del siglo XIX bajo el impacto de las actividades de compañías bananeras estadounidenses y del éxito económico de la exportación de plátano. Desde esta época, la ciudad ha sido el lugar de una feroz competencia para la inversión extranjera, impulsada en los ochenta por medidas de desregulación sucesivas. Concentra 40\% del empleo en el país y más de 65\% del empleo en las maquiladoras. Estas últimas se dedican en gran parte al ensamblaje en el sector textil y de confección. ${ }^{3}$ Su capital pertenece $38 \%$ a empresas estadounidenses, 28\% a empresas asiáticas y $17 \%$ a empresas hondureñas (Hardy, 2006).

Pero la prosperidad no puede esconder la inestabilidad del mercado laboral responsable de la situación precaria de miles de trabajadoras. En las maquilas, las condiciones laborales son duras y los salarios insuficientes. De la población de la región Cortés 80\% vive en la pobreza, y la mano de obra de las maquiladoras se aloja principalmente en asentamientos informales con infraestructura básica deficiente. Paralelamente, las inversiones públicas apoyan las actividades de las maquiladoras, sin tomar en cuenta las necesidades de la población. La elección sucesiva a la presidencia de la República de Ricardo Flores Facussé (1998-2000) y de Ricardo Maduro (2000-2004), los dos empresarios en San Pedro Sula, es demostrativa del poder de la oligarquía de Cortés. Esa oligarquía intenta por una parte imponer la región como modelo de desarrollo para el resto del país y por otra preservar sus ventajas económicas comparativas controlando una de las zonas más competitivas en materia de maquiladoras. ${ }^{4}$ Las grandes desigualdades en esta ciudad así como la buena conexión internacional constituyen factores muy favorables para la emigración. A las grandes desigualdades económicas se suma la visibilidad del "sueño americano" en San Pedro Sula. Existen vínculos tradicionales con Nueva Orleans y la ciudad cuenta con una fuerte presencia de restaurantes, centros 
comerciales y productos norteamericanos. Cortés, con un índice migratorio de 13\%, es la región de más emigración en el país (Rivas Castillo, 2008).

\section{El trabajo en las maquilas, un factor de emigración}

Las maquiladoras son un lugar de trabajo muy común. En Honduras como en otros países, se favorece la vinculación de mujeres a las fábricas de confección. De hecho, existe en el reclutamiento una selección según la cual se percibe en el cuerpo de las mujeres capacidades esenciales diferentes a las de los hombres. Se reclutan mujeres en maquiladoras como si tuviesen ojos más dispuestos para percibir los detalles y manos delicadas y hábiles para coser, soldar o tornar componentes minúsculos (García Aguilar, 2008). Se observa una situación comparable por ejemplo en el sur de España, donde se reclutan mujeres extranjeras para la cosecha de frutas pequeñas como las fresas (Burchianti, 2006).

El trabajo en las maquiladoras de Honduras "principalmente ensamblaje industrial" es rutinario y fastidioso. Los horarios y las actividades de producción están cuidadosamente controlados. Por lo general, los trabajadores se tienen que registrar en la entrada. El mercado laboral es muy inestable, basado en una rápida rotación de la mano de obra y un fuerte ritmo de aperturas y cierres de fábricas. Se ejerce perpetuamente la presión de un posible despido sobre las trabajadoras. El despido ocurre muy fácilmente incluido por causa de accidente o de embarazo. El sindicalismo está menos organizado que en otras unidades de producción y muy a menudo severamente reprimido (ElBoletín, 2010).

Por otra parte, los estudios sobre las trabajadoras industriales de la frontera norte de México dan evidencia empírica de que el entorno laboral de las maquiladoras genera distancia con el hogar y el papel tradicional de la mujer percibido por los hombres (Staudt y Vera, 2006). De hecho, el ritmo laboral de las fábricas aleja las mujeres del hogar. Además, la percepción de ingresos y la sociabilidad que se puede construir dentro de la maquila a través del contacto con las colegas de trabajo o del sindicalismo puede generar una forma de autonomización social (Swanger, 2007). Así, los ingresos y la emulación colectiva pueden facilitar la toma de la decisión de emigrar y también el pago de la ruta hacia "el norte".

Tal potenciación está a menudo rechazada por las sociedades urbanas que incluyen las maquilas. Además, el aislamiento social y el anonimato de las ciudades con fuerte acrecencia demográfica son factores que facilitan las agresiones y violaciones en contra de las mujeres. Ellas sufren de la pasividad de las autoridades y encuentran muy pocos defensores de su autonomía en la sociedad (Staudt y Vera, 2006). Los fenómenos de las pandillas y del crimen organizado crecen en San Pedro Sula, y los feminicidios son más y más frecuentes en las zonas donde se concentran las maquilas. Los indicadores de violencia intrafamiliar y de crímenes en contra de las mujeres están cada vez más altos en dichas zonas (Gargallo, 2005).

Durante el trabajo de campo en Frontera Comalapa, todas les emigrantes encontradas definieron situaciones de violencia intrafamiliar o de ruptura con su esposo como una causa, primaria o secundaria, de su emigración. Así, el contexto económico próspero de San Pedro Sula no se puede separar de un contexto social de amplia violencia en contra de las mujeres, cuya escapatoria suele ser citada como causa de emigración. Aquí se citan dos extractos significativos de entrevistas:

Mi madre se fue primero por causa de problemas con mi papá. Se fue con su madre. Después llegó la caída de los precios del plátano y de la caña más la llegada de los chinos y de los coreanos que abrieron las maquiladoras de confección. Vivimos bien económicamente. Pero mi padre empezó a tener comportamientos violentos conmigo y era más y más difícil para mí soportarlo [...] después de eso tomé la decisión de irme como se fue mi madre (Rosa, 26 años, ama de casa y ambulante, en Frontera Comalapa desde 1999).

-Usted medicequeconsu empleoen las maquiladoras 
[de Honduras] tenía más o menos 1,300 pesos al mes. Y aquí [en México] usted tiene 1,500 pesos al mes como costurera..

-Yo no me fui por el dinero, me fui porque me separé de mi marido y era una situación de crisis en mi vida. De crisis muy grave (Lucia, 42 años, costurera y ama de casa, en Frontera Comalapa desde 1996).

Se ve entonces en San Pedro Sula, la emigración no solamente es causa de las desigualdades económicas y los vínculos con Estados Unidos de América, sino también por una situación de violencia en la cual las mujeres se encuentran más vulnerables que los hombres. Además de la pérdida de sus empleos en las maquiladoras y de la separación con el esposo, las entrevistadas mencionaron la carencia de seguridad pública y de estructuras de educación y de salud para sus niños. Así se puede concluir que la emigración no se explica únicamente en términos económicos sino también en términos sociales que tocan particularmente a las mujeres. El género constituye entonces un eje de las causas de la emigración hondureña.

\section{Mercado laboral y migración en Frontera Comalapa}

\section{Situación económica}

Muy escasos son los datos sobre la economía de Frontera Comalapa. En el año 2000 la población económicamente activa se dividía entre 52,97\% en el sector primario, $10,78 \%$ en el sector secundario y $34,62 \%$ en los servicios. El promedio de la región fronteriza, respectivamente de 57,40\%, 12,33\% y 28,61\% (Instituto Nacional para el Federalismo y el Desarrollo Municipal, Gobierno del Estado de Chiapas, 2005). La prosperidad relativa del municipio en la región fronteriza se puede vincular con la preeminencia de los empleos en el sector de los servicios. De hecho, por su situación geográfica de Frontera Comalapa, en la intersección entre la carretera panamericana y la frontera con Guatemala, mantiene un constante flujo de personas y mercancías, por lo que los sectores relacionados "hoteles, reparación de automóviles, prostitución etcétera” perciben ingresos significativos. Estos empleos se concentran en la cabecera municipal, en donde operan los hoteles, restaurantes, talleres de reparación y cantinas. El sector de la construcción también se ve favorecido. Durante el trabajo de campo, un hospital así como varios proyectos de empresas en la cabecera municipal, como un nuevo hotel en la entrada de la ciudad, estaban en proceso de edificación. La prosperidad de Frontera Comalapa sobresale en comparación con los municipios de los alrededores, Chicomuselo o Amatenango de la Frontera, de recursos más escasos. La cabecera cuenta con cajas de préstamo de dinero y varios comercios, entre ellos un supermercado y una tienda de artículos electrodomésticos. Por otra parte, la economía del municipio está cada vez más vinculada con el narcotráfico, lo que mantiene la presencia militar y una creciente inseguridad como lo mostraron varios incidentes violentos (Cordero y Pérez, 2009).

Los empleos ocupados por los y las migrantes

A pesar de que no existen datos cuantitativos sobre los empleos ocupados por los migrantes en Frontera Comalapa, ${ }^{5}$ algunas observaciones cualitativas son posibles.

En la agricultura, parte de la fuerza laboral es constituida por trabajadores temporales, principalmente de Guatemala. Para las obras públicas, se utiliza generalmente como mano de obra a los migrantes de paso.

Los trabajos puntuales de reparación o jardinería en las casas privadas están a menudo realizados por migrantes de paso que se encuentran reclutados por los habitantes a quienes les pagan un precio inferior al que sería pagado a mexicanos. En la mayoría de los casos, los centroamericanos están empleados en condiciones muy 
desfavorables garantizadas por la amenaza de denuncia a las autoridades, de no pago y la rápida renovación de la mano de obra.

Unos niños vienen de Guatemala para practicar como chicleros. En Frontera Comalapa, se encuentran en competencia con otros, llegados de la región de Los Altos, en el centro de Chiapas. Por último, algunos mendigos que provienen de Centroamérica se instalan en la ciudad durante los períodos en los que pueden beneficiarse de la generosidad de los habitantes "feria, celebraciones culturales etcétera". A menudo, tienen una discapacidad como consecuencia de accidentes o ataques sufridos en Estados Unidos o durante su viaje a este país. Esta situación les garantiza una cierta tolerancia de parte de las autoridades.

Una minoría de comerciantes guatemaltecos llega con suficiente capital financiero para iniciar un pequeño negocio "por ejemplo, una peluquería" e instalarse en la ciudad. Por tener capital que permite actividad estable e independiente, experimentan menos dificultades que los otros trabajadores extranjeros.

Así resumimos que con la excepción de la última minoría, los hombres extranjeros ocupan empleos de manera temporal y después se regresan a Centroamérica, o siguen adelante en dirección a los Estados Unidos de América.

Los empleos que ocupan las extranjeras que llegan solas ${ }^{6}$ y las hondureñas en particular son muy diferentes. Las actividades que pudimos identificar en el caso de las hondureñas son las siguientes: vendedora en tiendas, ambulante, cocinera, empleada doméstica, ama de casa, mesera. Como en muchos lugares del mundo donde la migración femenina va en aumento, los empleos recurrentes se dan en la manufactura industrial y en los servicios principalmente relacionados con el trabajo doméstico, la preparación y servicio de alimentos o la prostitución (Morokvasic, 2007).

Se puede concluir que el mercado laboral de las poblaciones migrantes en Frontera Comalapa está muy generalizado. Además, el empleo depende de la situación en la cual las personas llegan a Frontera Comalapa. Por ser más aisladas y detener menos dinero - o estar más expuestas a ser robadas - las mujeres se encuentran en situaciones más inestables, lo que las empuja a aceptar empleos de menor calidad. Además, existe una selección en el mercado laboral comalapense que dirige a las mujeres hacia los servicios.

Por fin, se nota que la migración femenina es mucho más homogénea que la migración masculina. De hecho, los hombres migrantes provienen de todos los países centroamericanos y a veces de otros países de las américas y del mundo. Las mujeres que llegan solas a Frontera Comalapa son en su mayoría de Honduras y del Salvador, de zonas urbanas e industriales en estos países. Así, como ya vimos, llegan de ámbito urbano y están acostumbradas a empleos del sector secundario o terciario, para integrarse al motor económico de la ciudad que es el sector de los servicios. Por eso, la presencia de trabajadores temporales agrícolas es fuerte en los municipios de los alrededores, pero los empleos ocupados por hondureñas se concentran en Frontera Comalapa.

\section{Evolución social de las inmigrantes hondureñas en el mercado laboral y la sociedad comalapense}

\section{Elementos de discriminación en un ámbito laboral generalizado}

Con respecto a los empleos domésticos, de ama de casa o de cocinera, se constata que en Chiapas como en otras partes del mundo se emplean mujeres por causa de la creencia en sus capacidades innatas en materia de atención a niños, de capacidad a cocinar o de cuidar el hogar en general. En 2005, el Instituto Nacional de Migración, INM, publicó cifras según las cuales entre 10\% y 14\% de los permisos de trabajo para los estados de Chiapas y Quintana Roo están destinados a mujeres que se dedican al trabajo doméstico. Uno puede imaginar que el porcentaje de mujeres que se dedican al trabajo doméstico con respecto al total de los migrantes es aún más importante. 
La contratación de migrantes sean internos o internacionales para el trabajo doméstico es una constante en Chiapas, aunque los estudios sobre el tema son escasos (Kauffer, 2008). Los limitados datos disponibles sugieren que la mayoría de los migrantes que trabajan como empleados domésticos en ciudades como Tapachula, San Cristóbal de Las Casas y Tuxtla Gutiérrez, son indígenas (Mirailles, 2007; Kauffer, 2008). Esta contratación preferencial depende en buena parte de una creencia común en la sociedad mexicana de que las mujeres indígenas son más eficaces en el trabajo doméstico y menos propensas a quejarse sobre sus condiciones de trabajo. Así pues, aunque no hay cifras sobre el tema, la contratación de domésticas en Frontera Comalapa parece girar más hacia las inmigrantes guatemaltecas que, a diferencia de las hondureñas, son en alta proporción indígenas.

\section{El estigma de la "quita maridos"}

La percepción de las hondureñas es muy diferente de la que se tiene de las otras mujeres extranjeras. Está principalmente orientada alrededor del estigma de la "quita maridos", que si no es adoptado por todos sí constituye la única referencia que circula sobre ellas en el municipio. Cuando se trata del asunto con habitantes del municipio, aparece a menudo esa imagen. Puede ser por ejemplo para decir que la prostitución es un factor de prosperidad, que la población hondureña es nociva por incitar a comportamientos inmorales o que, por ser víctimas de redes ilegales, las migrantes necesitan asistencia. Los siguientes testimonios, de un propietario de una granja, un profesor, y un cliente de cantina, son emblemáticos de la visión que predomina en los hombres del municipio acerca de las hondureñas:

¿Por qué la gente prefiere las de Honduras? Porque la gente hace la diferencia aquí [...] ya sabes, ven la llegada de una guatemalteca y dicen que es indígena, que no es realmente bonita. Las mujeres de Honduras y El Salvador son de piel más blanca, más sexys, más atractivas. Luego viene el momento que un mexicano va con ella [...] pero nunca se van a casar civilmente, unas veces en la iglesia. Pero los hombres aquí se vuelven locos, dejan a sus esposas e hijos para vivir con ellas. Conocí a un abogado, tenía una casa, tres o cuatro hijos en Motozintla. Ha dejado todo su gabinete y todo, sus niños, y ahora vive con su hondureña en Frontera Comalapa...

Bueno, lo que tengo que decir con las hondureñas es que mucha gente les está estigmatizando. Mucha gente se queja que vienen para trabajar en los bares o en la zona de tolerancia [] para quitar maridos... Pero no tengo ese tipo de discurso, yo digo que no es una cosa tan mala porque mira, antes, en la ciudad no tenía dinero. Ahora si viene el dinero por todas las cantinas que tenemos. Es que la prosperidad de la ciudad, hay que recordar que la tenemos gracias a ellas.

Las hondureñas? Sí, claro que son las más bonitas. Dices que estás buscando un bar si quieres te llevo, en serio, tiene un bar allá todas tienen en sus dieciséis años. [] Bueno, digo muy bonitas [...] el problema es que se tiene que ir en busca de las demás, porque cada vez que llegan, empiezan a trabajar en bares y luego después de que beben tanta cerveza, se engordan ... y se tiene que ir por más carne fresca (risas). Pero sí que son bonitas..

Aquí se hace alusión al trabajo en las cantinas que implica una exposición a la violencia, la humillación y el consumo diario de alcohol, bajo la presión del sistema de remuneración de fichas ${ }^{7}$ de lo que es visto como una alteración del cuerpo, único elemento detrás del cual esta gente desaparece por completo. Así, las inmigrantes hondureñas se encuentran en una situación "que les descalifica y les impide ser plenamente aceptadas por la sociedad", lo que en la perspectiva de Erving Goffman (1975) corresponde a la construcción de un estigma.

En los hechos, sólo una parte de las hondureñas trabajan en el ámbito de los bares o en la zona de 
tolerancia. Además, esta experiencia es limitada en el tiempo. Pero esta actividad es la única que aparece en el discurso de los habitantes, también la que más proponen a las migrantes que llegan a la ciudad. Se opera así una selección de imágenes relacionadas con las hondureñas que influyen en el ámbito social y laboral.

Se puede hacer un paralelo entre esa situación y la idea desarrollada por Foucault en su Historia de la sexualidad (1976). Se puede constatar que el papel de las hondureñas siempre está influenciado por su cuerpo y el problemático reconocimiento de ellas como madres o como personas que pueden tener un lugar en un hogar familiar. Foucault (1976) ha definido el papel del sexo como un elemento estructurante en la sociedad y en su economía a través de la gestión de los hogares. Así podemos suponer que la estigmatización de las hondureñas y su concepción como gente que tiene que quedarse por fuera de todo matrimonio oficial implica dos cosas. Primero, como población invisibilizada y percibida como exterior a la comunidad municipal, sirve para que los hombres cumplan con las normas de tener una vida sexual antes del matrimonio mientras que las mujeres del municipio cumplan con la norma de confundir su vida sexual con la reproducción y el matrimonio. Segundo, las hondureñas están percibidas como mujeres que trabajan fuera del hogar y que ya dejaron uno en su país de origen. Esa percepción implica que no podrían manejar recursos en un entorno matrimonial sin poner en riesgo los recursos del esposo y la educación de los niños.

\section{Condiciones laborales y papel en la economía y la sociedad comalapense}

\section{Los empleos en las cantinas}

La alta demanda de sexo servicio en Frontera Comalapa se debe a la situación geográfica de la ciudad, por una parte colocada en un cruce de carreteras principales y por otra rodeada por municipios que carecen de zona de tolerancia. La militarización de la zona y la normalidad del uso de la prostitución en la iniciación sexual en los jóvenes acentúan también el fenómeno. De hecho, la mitad de la población masculina en Chiapas tuvo su primera relación sexual con una prostituta. Tal relación es a menudo seguida por otras del mismo tipo (Kauffer y Evangelista, 2008). Un punto importante de la dependencia a la prostitución es la presión social contradictoria operada por una parte sobre los hombres jóvenes para empezar su vida sexual tan pronto como sea posible, y por otra parte sobre las mujeres para asociar sexualidad, matrimonio y reproducción. Este fenómeno necesita la creación de un grupo de mujeres que sea considerado como exterior a la población del municipio, para que las relaciones sexuales fuera del matrimonio sean accesibles a los hombres sin serlo para las mujeres.

Según los testimonios de los habitantes, antes de la creación de la zona de tolerancia vinieron trabajadoras sexuales de Comitán que fueron reemplazadas por centroamericanas después de la creación de dicha zona en los años setenta. Empezó la explosión del número de cantinas y el ejercicio de la prostitución clandestina en la segunda mitad de los noventa. Tal fecha corresponde por una parte con la llegada de la primera ola migratoria de hondureñas, y por otra con el aumento de la militarización en el estado. La explosión del número de cantinas en las cuales ejercen mujeres extranjeras se puede también relacionar con la presencia de redes ilegales y la existencia del fenómeno de la trata de personas en la región.

Así vemos como, con la articulación una alta demanda de sexo servicio con las percepciones que existen del cuerpo de las hondureñas, se mantuvo separado un grupo de población femenina cuya función necesitaba ser excluida de la población del municipio. Nos parece uno de los elementos principales que explican la estigmatización de las hondureñas y de los matrimonios que las incluyen. 
Los ingresos generados por la actividad de mesera o la prostitución - clandestina o no- dependen del aspecto físico de la persona que la ejerce. Así es según criterios de apariencia que los clientes tienen más o menos probabilidad de invitar a una a su mesa. Las hondureñas son las más solicitadas en la materia. Así, son ellas que pueden consumir más con los clientes y generar más ingresos con el sistema de las fichas. Están seguidas por las salvadoreñas en la jerarquía establecida por la demanda de los clientes. Sin embargo, la presencia de estas últimas es mucho menor que la de las hondureñas. Después vienen las guatemaltecas, quienes tienen la reputación de ser menos bonitas. Las meseras mexicanas y de otras nacionalidades son mucho más minoritarias y casi no se habla de ellas en las conversaciones con los clientes. Así, por el mero hecho de ser hondureña, una mujer puede fácilmente encontrar un empleo en el ámbito de las cantinas. La demanda y el sistema de pago les garantiza ingresos estables y mayores que en otros puestos de trabajo reservados para los inmigrantes.

Sin embargo, trabajar en las cantinas o en la zona de tolerancia expone a muchos riesgos. Primero, el sistema de fichas implica una fuerte dependencia del patrón, quien puede ejercer la presión de no pagar una. Además, los ingresos dependen del consumo de alcohol y de las bebidas que los clientes toman con las meseras. Eso primero implica un problema de salud, así que el consumo diario de alcohol en gran cantidad expone a riesgos. El consumo de cervezas en gran cantidad implica también problemas de peso, lo que influye sobre el aspecto físico y la correspondencia con las expectativas de los clientes. La competencia entre meseras se ejerce también sobre la resistencia al alcohol. De hecho, es muy mal visto entre las meseras emborracharse rápidamente y de dejarse tocar por los clientes o de tener relaciones sexuales con ellos en cambio de dinero. Así, se crea una situación de presión entre las meseras y también con los clientes. El objetivo es, por una parte, tomar lo más posible con los clientes y mantener en ellos un deseo de seguir consumiendo, y por otra de no dejarse tocar o practicar la prostitución. Tienen la cabeza más alta quienes lograron generar más ingresos sin dejarse emborrachar o tocar. Son ellas que después podrán decir frente a sus colegas que no necesitan venderse.

Sea en las cantinas o en la zona de tolerancia, el trabajo femenino es sujeto a un enorme control físico y social de parte de los patrones, de la población y de las autoridades. Eso sin garantizar la seguridad física o sanitaria de las trabajadoras. Así, las lógicas de evolución en este ámbito no existen realmente y se acercan más a la sobrevivencia. No apareció en la investigación cualquier beneficio de las actividades en las cantinas aparte de los ingresos. Las mujeres que quieren irse por otro empleo se encuentran a menudo restringidas por la dependencia económica al patrón o el riesgo de denuncia a las autoridades migratorias. Una parte logra tener una situación más estable y reconocida pero pocos son los casos en los cuales lo logran solas, y sufren a menudo de la carencia de una red social.

\section{Condiciones laborales en los otros empleos}

A pesar de que las actividades de las hondureñas consistan en las tareas más arduas, nunca están socialmente valoradas como empleos. La remuneración es a menudo percibida por el empleador como un favor, dada su concepción de las dificultades económicas de las migrantes. Además, la regularización administrativa por razones laborales es inaccesible por el carácter informal de los empleos ocupados o muy a menudo por falta de voluntad de parte del patrón de participar en el trámite. Los empleos tales como los de cocinera, empleada doméstica o ama de casa siempre se consideran como un "apoyo" a otras actividades consideradas principales, aún más cuando se ejercen dentro del matrimonio.

A los mecanismos generalizados se añaden la condición de extranjera y la falta de una red social a su llegada a Frontera Comalapa, la migración desde 
Honduras es muy reciente y las migrantes están aisladas unas de otras ${ }^{8}$. Trabajar en el municipio implica la sucesión de empleos altamente inestables como el comercio ambulante o el trabajo doméstico. En este último, los horarios extensibles de trabajo se suman a una posibilidad permanente de despido, a menudo decidido por una simple sospecha de robo o de relación con uno de los hombres de la familia empleadora. El hecho de tener contactos en Frontera Comalapa en el momento de la partida de Honduras sirve a la condición precisa de que el contacto movilizado se encuentre en una situación estable. De hecho, las que conocen a una empleada en una tienda o personas ya casadas pueden ser recomendadas para empleos más estables, pero constituyen una minoría. La mayoría de las migrantes que llegaron con un contacto en la ciudad se incorporaron a trabajar apoyando el empleo de su contacto sea en una cantina o como doméstica. Así, cuando existe la red social, no necesariamente es un factor de mejoramiento de la situación laboral.

\section{El matrimonio y el trabajo en el hogar}

Con excepción de las que encontraron un trabajo como empleadas en algún comercio, las perspectivas de evolución en el ámbito laboral son muy escasas. A esa situación se tiene que añadir el hecho de que muchas no quieren regresar a Honduras por la situación de crisis social que huyeron o por una ruptura con la red social que tenían antes de emigrar. La falta de voluntad de regresar a Honduras excluye la posibilidad de reinvertir allí el dinero ahorrado en México. La única oportunidad de evolución socioeconómica que se les ofrece entonces será el matrimonio. Este último, escogido o no, será al mismo tiempo una estrategia de salida de actividades que implican una situación humillante o de labor agotadora.

Si el matrimonio implica una mejoría de la situación material, tiene también por consecuencia el sacrificio de la autonomía financiera y administrativa. Se pierde a menudo un empleo independiente para apoyar a la actividad de su esposo, cocinando en el caso que tenga un restaurante o trabajando en la tienda en el caso de un negocio. Si el esposo es empleado, las mujeres participan con los ingresos familiares mediante actividades como la venta ambulante o la costura, que se añaden en todos los casos al trabajo doméstico.

\section{Conocer y aplicar sus derechos como extranjera}

La mayoría de los estudios sobre derechos de los migrantes en México se dedican a la situación de los migrantes de paso (FIDH, 2007; Rivas, 2008). El caso de los migrantes que se quedan implica en el largo término los mismos derechos que ya están menospreciados en el caso de los migrantes de paso, como el acceso al trabajo declarado, la seguridad o la salud. Además, implica otros derechos como el acceso a la educación para los niños o el acceso a la protección social. En el estado de Chiapas, y especialmente en el municipio de Frontera Comalapa, se puede constatar que las instituciones no están preparadas para dar a una población extranjera acceso a los mismos derechos que a la población mexicana.

\section{Situación administrativa y regularización}

En México, el documento que se puede otorgar a las personas que regularizan su situación administrativa después de una entrada irregular en el territorio es el FM3. "Forma Migratoria 3" es un permiso de estancia en México de un año renovable. Un extranjero la puede obtener si comprueba su autonomía económica o su dependencia a una persona mexicana o en situación regular. ${ }^{9}$

A pesar de que existe desde 2008 un programa de regularización, muy pocos permisos para permanecer en México se han entregado a hondureñas entre enero de 2006 y julio de 2008. El número de FM3 entregados a ciudadanos hondureños por la oficina de INM en 
Tapachula, de la cual depende el municipio de Frontera Comalapa, era 316 en ese período. Que se puede considerar como muy inferior a la población hondureña presente en el estado (Fernández, 2009).

La regularización corresponde entonces a una pequeña minoría que logra tramitar el FM3, con pruebas escritas de vida matrimonial con un mexicano o de trabajo estable y declarado con ingresos suficientes. Como lo vimos más arriba, la probabilidad de encontrarse en tal situación ya presenta dificultades. Además, para las que logran cumplir con los requisitos, empieza un largo camino hacia la obtención del FM3. A eso se le tiene que añadir el desconocimiento de las condiciones de regularización por las migrantes en general y la percepción de la regularización como un logro inaccesible.

Casi todas las hondureñas presentes en Frontera Comalapa entran a México sin pasaporte ni visa, a menudo sin ningún documento oficial de identidad. Pero para el trámite de regularización necesitan presentar un pasaporte válido. Eso fue descrito por las entrevistadas como la etapa más difícil del proceso de regularización. De hecho, muchos de los consulados de Honduras en el extranjero son ahora incapaces de emitir pasaportes, ${ }^{10}$ en parte porque los pasaportes que emitían hasta ahora ya no son aceptados por Estados Unidos y varios países asiáticos y europeos. Eso tuvo como consecuencia muchas quejas de parte de hondureños que tenían que desplazarse a otro país, también por casos de corrupción o de retrasos interminables (La Prensa de Honduras, 2008 y 2009). Los hondureños que viven en Chiapas solamente pueden sacar el pasaporte en Honduras, lo que tiene un precio y un riesgo considerable. El pasaporte cuesta sesenta dólares —aproximadamente 750 pesos mexicanos-11 y su obtención está condicionada al requerimiento de documentos, entre otros el acta de nacimiento o la cédula - equivalente hondureño de la credencial de elector mexicana-, que también se tienen que sacar en Honduras.
Además del precio del pasaporte, el FM3 cuesta entre 1,000 y 1,600 pesos ${ }^{12}$. Así, la regularización cuesta aproximadamente 2,000 pesos de trámites administrativos, a lo que se agregan los gastos de transporte hasta Honduras y hasta Tapachula. Tal precio es un motivo de desánimo para las que podrían regularizarse. Adicionalmente, se tiene que pagar de nuevo cada año para sacar el nuevo documento. Así ocurre que por falta de dinero personas que ya estaban regularizadas no renovaron el trámite y se encontraron de nuevo en situación irregular.

A parte del precio, la regularización por vínculos familiares depende de la prueba de los vínculos conyugales con un mexicano y de una estancia superior a tres años en México. Se hace con constancias de los presidentes de barrio, certificadas por el ayuntamiento. Su expedición depende a menudo de las buenas relaciones con dicho presidente. Al parecer, por la sociabilidad los presidentes de barrio y el tamaño más pequeño de la ciudad, las constancias se obtienen más fácilmente en Frontera Comalapa que en una ciudad más impersonal como Tapachula (Fernández, 2009). A pesar de eso, la dimensión informal del trámite es un arma de doble filo ya que se vuelve más difícil en caso de malas relaciones con las personas influyentes del barrio.

A eso hay que añadir el hecho que el trámite es muy pesado y la administración migratoria muy lenta. Las candidatas a la regularización se encuentran a menudo obligadas a ir y venir muchas veces a las oficinas de INM para añadir y actualizar las piezas que faltan. Por otra parte, la falta de información y la dimensión infantilizante de un trámite que siempre pide justificarse a una población que vive en México desde muchos años acaba a veces por desmotivar las personas las más temerarias.

\section{Acta de nacimiento y ejercicio de los derechos de los niños}

En un informe sobre el acceso al acta de nacimiento en México publicado en 2009, Unicef considera que 
"[el acta de nacimiento es] un documento clave para la identidad ciudadana, para el ejercicio de los derechos y obligaciones [y] un instrumento de protección de la persona" (Unicef, 2009). El mismo informe hace hincapié en la carencia de documentos de estado civil en la población chiapaneca, especialmente en las regiones rurales, campesinas e indígenas. Estas zonas han sido objetos de varias campañas de registro en la década del año 2000 a través de oficinas móviles. Mas recientemente, y sin que los resultados puedan ser visibles, ocurrieron capacitaciones a funcionarios del registro civil de algunos municipios fronterizos para dar acceso más efectivo al estado civil de los niños de extranjeros. ${ }^{13}$ Por el momento, no ha ocurrido tal campaña destinada a la población descendiente de migrantes en el municipio de Frontera Comalapa. ${ }^{14}$ Además, los datos de campo muestran que muchos niños de madre extranjera, y más precisamente de madre hondureña, carecen de acceso efectivo al estado civil y a sus actas de nacimiento.

De la consulta del expediente de los niños nacidos de padres extranjeros del registro civil en Frontera Comalapa, se encontraron 92 actas de nacimiento para niños de los cuales por lo menos uno de los dos padres es hondureño entre 1999 y 2008.15 Aunque faltan datos sobre el número exacto de ciudadanos hondureños en Frontera Comalapa, se puede suponer que muchos más niños nacieron.

La primera causa por la cual no se registran esos niños es la falta de documento de identidad de la madre y su falta de estancia legal en México. El registro civil no necesita la legalidad de la estancia de los padres si se declara el niño en los seis meses que siguen al nacimiento. Sin embargo, esa información es muy poco conocida por las hondureñas. La mayoría deja pasar los seis meses y teme además presentarse ante una autoridad sin encontrarse en situación administrativa regular. Además, se requiere una constancia de nacimiento. Cuando ocurre el parto en el centro de salud, se puede obtener la constancia al presentar un documento de identidad. El problema que ocurre a menudo es que las personas extranjeras no cuentan con documentos de identidad, aunque sean documentos de su país de nacionalidad. En el caso de partos que ocurren fuera del centro de salud, la constancia se obtiene por intermediario de la partera que intervino. Al entrevistar dos parteras en la cabecera municipal testimoniaron que, varias veces, el personal del centro de salud no aceptó darles una constancia por el motivo que la madre era hondureña y soltera.

La primera consecuencia para los niños es la falta de nacionalidad. De hecho, en virtud del artículo 30 de la Constitución del país, México aplica las disposiciones siguientes:

La nacionalidad mexicana se adquiere por nacimiento o por naturalización.

A)- Son mexicanos por nacimiento:

I.- Los que nazcan en el territorio de la República, sea cual fuere la nacionalidad de sus padres (XIII Edición de la Constitución mexicana, 2009).

Así, los niños nacidos de hondureñas en Frontera Comalapa son mexicanos como todos los niños nacidos en suelo mexicano. Pero, sin acta de nacimiento, se les puede rechazar todos los derechos inherentes a la nacionalidad mexicana, como por ejemplo la estancia en el país. Durante una visita al consulado hondureño en Tapachula, se encontró una mujer de la cual el hijo de 19 años, nacido en México, se había ido a Estados Unidos en compañía de otros mexicanos. Se encontraba al momento en una estación migratoria en el norte del país y las autoridades mexicanas estaban a punto de deportarlo a Honduras, un país que nunca había visitado en su vida. En la mayoría de los casos, como las emigrantes no mantienen vínculos con Honduras y no regresan al país, los niños se quedan sin nacionalidad ninguna. Así, no tienen derechos como ciudadanos, sean políticos, sociales o económicos, en ningún país. 
El artículo 3 de la Constitución mexicana garantiza el acceso a la educación para todos sin distinción. Sin embargo, el acta de nacimiento, mexicana o extranjera, es un documento exigido en todas las escuelas en Chiapas. Así, muchos de los niños que no tienen ni acta mexicana ni acta hondureña se encuentran con un acceso restringido a la escuela. En Frontera Comalapa, algunas instituciones permiten la entrada de los niños al jardín de niños sin acta. Pero el acta es a menudo necesaria para obtener los certificados que permiten la entrada a la escuela primaria o secundaria.

Una consecuencia más de la carencia de acta es el establecimiento de la filiación del niño. De hecho, ningún otro documento oficial determina los vínculos familiares. Eso puede causar problemas en asuntos de sucesión, de unidad familiar o de separación de los padres.

\section{Acceso a la salud}

Las hondureñas en Frontera Comalapa se encuentran ante las mismas deficiencias del sistema de salud que los mexicanos urbanos, quienes no tienen acceso al sistema de seguridad social (aproximadamente el 70\% de ellos, de acuerdo con el INEGI, 2005). Las que se encuentran en situación regulary tienen derecho al régimen de seguro social de su esposo, como por ejemplo el IMSS en el caso de los empleados, sufren discriminación por causa de una creencia bastante generalizada de que el seguro social es un privilegio de los nacionales. La situación irregular de la mayoría de las migrantes les hace más vulnerables a la corrupción, y las posibilidades de queja en caso de negación de asistencia son nulas. Todos esos problemas se encuentran agravados por el hecho de que en México no existen estadísticas sobre los problemas de salud de los extranjeros o los vinculados con la migración. Esa invisibilización se añade a la falta de voluntad politica para impedir toda posibilidad, por el momento, de elaborar programas públicos de atención médica dirigidos a los migrantes.

\section{Conclusiones}

Podemos concluir que las relaciones de género en el trabajo y la exclusión a través de los órganos de administración son factores que mantienen a la población femenina hondureña "aparte" de la sociedad comalapense, aunque participe de múltiples aspectos de la sociedad local y mantenga diversos vínculos con ella.

Sin embargo, el hecho de que las hondureñas estén relegadas a ciertos empleos del sector servicios y solicitadas por la población masculina les permite organizar estrategias de emigración y de movilidad social. De hecho, la prosperidad de la ciudad y los empleos que propone la transforman cada vez más de un lugar de paso en una destino definitivo de emigración. Para las hondureñas llegadas entre 1998 y los últimos años, el paso en Frontera Comalapa permitía ahorrar dinero para financiar la ida a Estados Unidos. Poco a poco factores como el aumento del peligro de la ruta hacia el norte (Ruiz, 2003) y el inicio de una vida matrimonial, constituyen una de las decisiones de quedarse en el municipio. Con la agudización de la crisis en Estados Unidos se ha constatado que más y más hondureñas llegan a Frontera Comalapa con la intención de establecerse en la ciudad y abandonan poco a poco la idea de cruzar al "otro lado".

Además, una parte de la población hondureña logra obtener una posición estable en la sociedad comalapense por medio del matrimonio y a veces por regularización administrativa. Así, las formas de dominación existen a través de las relaciones de género, sea en el ámbito laboral, familiar o sexual, no desaparecen sino se perpetúan en el contexto de la emigración. Simplemente, pueden ser utilizadas como apoyo en la realización de proyectos de movilidad social.

La situación de las emigrantes en Frontera Comalapa se encuentra hoy aún más complicada por causa de la extensión de las redes del crimen organizado y de la situación política en Honduras. Una progresión de la atención académica sobre el asunto permitiría avanzar 
más conclusiones sobre el papel de la agencia de las mujeres en la evolución de las relaciones de género en las situaciones de migración.

\section{Notas}

${ }^{1}$ El análisis de esta figura es complicado porque se basa en el censo de 2000 de Inegi sobre el país de nacimiento, cual las personas encuestadas tienden a ocultar en caso de situación irregular. En cuanto a la división por sexo, la tabla proporcionada por INEGI tiene una sola cifra decimal, lo que representa un margen de error de 255 personas entre los nacidos en Honduras, 6,5\% de ellos, de los cuales ignoramos el sexo.

${ }^{2}$ FM3 para "Forma Migratoria 3" es un documento forma migratoria aplicable para la calidad de "No Inmigrante" renovable al año. Es la forma migratoria que se otorga para quien regulariza su situación administrativa. Es también la que tiene entre la gran mayoría de la población hondureña que se encuentra en situación administrativa regular. Se diferencia del FM2 que es un documento destinado a personas que se instalan en México para residir definitivamente en el país.

${ }^{3}$ Estas cifras se explican en parte por el artículo 807 del Código Aduanero estadounidense, que ofrece grandes facilidades para la reimportación de productos textiles ensamblados en la Cuenca del Caribe.

${ }^{4}$ Los intereses conjuntos a la elite económica de San Pedro Sula y al ejército contra las reformas del presidente Manuel Zelaya durante el golpe de junio de 2009 es indicativo de la influencia de los empresarios de la región en el mundo político hondureño. (Baeza y Madueño, 2009).

${ }^{5}$ Sobre el asunto de las actividades de los migrantes en la frontera sur de México, leer los trabajos de Salvador Rivera.

${ }^{6}$ Con la excepción notable de las mujeres que llegan con familia, principalmente de Guatemala, para dedicarse a trabajos agrícolas temporales.
7 Para cada bebida tomada por o con un cliente, la mesera recibe una tarjeta laminada, cual cambia por dinero cuando el patrón lo decide. Es el único sistema de ingresos que existe para las meseras en Frontera Comalapa.

${ }^{8}$ Más que algo sufrido, esta situación parece una opción de parte de las emigrantes que no muestran ninguna voluntad de conectarse con otras migrantes hondureñas en México. Tanto como la falta de voluntad de regresar a su país de nacionalidad, el análisis de este hecho necesita más investigación pero parece resultar de una voluntad de disminuir lo más posible su visibilidad y de no atraerse problemas encontrados por otras.

${ }^{9}$ La Ley General de Población permite la estancia en México a las personas capaces de comprobar que tienen recursos suficientes, principalmente a través de un empleo estable o de la "dependencia económica", a un(a) esposo(a) (art. 52).

${ }^{10}$ Oficialmente desde el 28 de junio de 2008, según circular núm. 1330-DGAC/2008, de la Secretaría de Relaciones Exteriores de Honduras.

${ }^{11} 60$ dólares es el precio que fue declarado por las que habían ido a Tegucigalpa para sacar el pasaporte antes de febrero de 2009. Se desconoce el precio que se ejerce en Tegucigalpa, ya que únicamente los sitios Internet de las embajadas en Washington y en Canadá indican públicamente un precio que es en los dos casos de 60 dólares, http://www.hondurasemb.org/tarifas. html y http://consuladohonduras.moonfruit.com/\#/ pasaportes/4543581053, [8 de diciembre de 2010]. La conversión en pesos mexicanos es a 10 de diciembre de 2010.

${ }^{12}$ Los precios de 1,200 o 1,600 pesos se han mencionado en las entrevistas hechas en Frontera Comalapa pero se supone que hubo confusión entre el precio para la regularización y el precio para renovar el FM3. El autor no cuenta con información oficial ya que cambió la denominación de las formas migratorias en abril de 2010 y que el sitio internet del Instituto Nacional de 
Migración no fue actualizado. http://www.inami.gob. mx/index.php/page/Descripcion_de_Formas/es.html.

13 La organización Sin Fronteras IAP ha realizado recientemente la formación de los funcionarios en registros de municipios de la frontera sur. "Capacitan a Servidores del Registro Civil", en El Orbe, septiembre 26, 2009.

${ }^{14}$ No se trata aquí del caso de los descendientes de refugiados guatemaltecos que tienen una historia particular.

${ }^{15}$ Datos de campo.

\section{Bibliografía \\ Fuentes primarias}

XIII $^{\circ}$ edición de la Constitución Política de los Estados Unidos de México, 2009. http://www.cndh.org.mx/ publica/publica.htm, [7 de junio de 2010].

Federación Internacional de Derechos Humanos (2008), "México-Estados Unidos, Muros, Abusos y Muertos en las Fronteras", [1l de marzo], informe n 488/3, http://www.fidh.org/Muros-abusos-y-muertos-enlas-fronteras,5336 [ 7 de junio de 2010].

Foro Nacional para las Migraciones en Honduras(2008), http://fonamih.org/Pagina_17.htm.

INEGI (2005), Conteo de población y vivienda 2005. http://www.inegi.org.mx/est/contenidos/proyectos/ ccpv/cpv2005/Default.aspx, [7 de junio de 2010].

INEGI (2007), Los extranjeros en México, INEGI. www. inegi.gob.mx/prod_serv/contenidos/espanol/bvinegi/ productos/estudios/sociodemografico/ext_en_mex/ extraen_mex.pdf $>$ [7 de junio de 2010].

Instituto Nacional para el Federalismo y el Desarrollo Municipal, Gobierno del Estado de Chiapas (2005), Enciclopedia de los municipios de México, artículo "Frontera Comalapa", en http://www.e-local.gob.mx/ work/templates/enciclo/chiapas/municipios/07034a. htm [7 de junio de 2010].

Medecins du Monde (2007), "La Santé des migrants et leur acces aux soins fontiere Mexique - Étati-Unis", informe en línea, http://www.medecinsdumonde. org/fr/Publications/Publications/Les-rapports/A-1international/La-sante-des-migrants-et-leur-accesaux-soins-Frontiere-Mexique-Etats-Unis.

Rodríguez Chávez, Ernesto (dir.) (2006), Aspectos Generales de la Inmigración Actual en México, Algunas tendencias y características de la población nacida en el extranjero residente en México, 2000, México, INM.

UNICEF, presentación en línea de los programas de protección de la niñez en México, http://www. unicef.org/mexico/spanish/proteccion_6991.htm, [7 de junio de 2010].

\section{Fuentes secundarías}

Baeza, Cecilia (2008), "Flux migratoires et droits des migrants", en Paris, Observatorio Político de America Latina y del Caribe (OPALC).

Baeza, Cecilia y Madueño, Nicanor (2009), “Coup d'Etat au Honduras, analyse historique d'un phénomène nouveau", en serie de artículos en línea, Observatorio Político de America Latina y del Caribe (OPALC), http://www.opalc.org/web/index.php?option=com content\&eview=article\&id=314:coup-detat-au-hondurasun-regard-historique-sur-un-phenomene-nouveau$1 \&$ catid=124:democratie-et-representation\& $\mathrm{Itemid}=212$.

Barth, Frederick (1995), Les groupes ethniques et leurs frontières, Paris: Presses Universitaires de France.

Burchianti, Flora (2006) "La fresa amarga. Mobilisations autour des persécutions rencontrées par les travailleuses agricoles saisonnières étrangères dans la province de Huelva (Espagne)", en Asylon(s), núm. 1, octubre 2006, Les persécutions spécifiques aux femmes, http://www.reseau-terra.eu/article49l.html. Evangelista, Angelica y Kauffer, Edith (2009), "Iniciación sexual y unión conyugal entre jóvenes de localidades en tres municipios de la región fronteriza de Chiapas", en Ponencia del 19 de febrero al $\mathrm{VII}^{\circ}$ Congreso Centroamericano de Antropología en San Cristóbal de Las Casas, Chiapas, México. 
Foucault, Michel (1976), “L'usage des plaisirs”, en ,Histoire de la sexualité, Paris: Gallimard.

Fernández Casanueva, Carmen (2009), "Viviendo en un destino no planeado? Migrantes hondureños en la ciudad de Tapachula, Chiapas". Ponencia del 20 de febrero $2008 \mathrm{al} \mathrm{VII}^{\circ}$ Congreso Centroamericano de Antropología Social en San Cristóbal de Las Casas, Chiapas, México.

García Aguilar, María del Carmen y Tarrío García, María (2008), "Migración irregular centroamericana. Las tensiones entre derechos humanos, ley y justicia”, en Daniel Villafuerte Solís y María del Carmen García Aguilar (coords.), Migraciones en Centroamérica y en el Sur de México, México: Miguel Angel Porrúa Eds.

Goffman, Erving (1975), Stigmate, Paris: Minuit.

Hardy, Sébastien (2006), "La vallée de Sula (Honduras): Une marge triomphante? ”, en Mosella vol. XXVIII, núm. 3-4, Metz: Université Paul Verlaine, http:// hal.archives-vertes.fr/docs/00/14/81/39/PDF/ Mosella-2003.pdf, [7 de junio de 2010].

Jounin, Nicolas (2008), "L'ethnicisation en chantiers. Reconstructions des statuts par l'ethnique en milieu de travail", en Revue européenne des migrations internationales, vol. 20, núm. 3, http://remi.revues.org/ index2025.html, [7 de junio de 2010].

Kauffer, Edith (2008), "Mujeres indígenas, procesos migratorios y derechos humanos en la frontera sur de México", en Ponencia presentada en la "Consulta sobre las mujeres indígenas en los procesos migratorios", Instituto Interamericano de Derechos Humanos, San José, Costa Rica, 1-3 abril 2008.

Lamas, Marta (1996), El género: la construcción cultural de la diferencia sexual, México: UNAM, Miguel Angel Porrúa.

Mirailles, Marion (2007), Les bonnes migrantes. Leur construction par les effets de genre, d'ethnie et de classe, tésis de maestria en sociología dir. María Eugenia Costo Zavala, París: Institut des Hautes Études sur l'Amérique Latine (IHEAL), Université Paris III.
Morokvasic, Mirjana (2007), "Migration, Gender, Empowerment", en Ilse Lenz, Charlotte Ullrich, Barbara Fersch (coords.), Gender Orders Unbound. Globalisation, Restructuring and Reciprocity, Farmington Hills: Barbara Budrich Eds.

Rivas Castillo, Jaime (2008), Migrantes Centroaméricanos y Organizaciones Civiles de Apoyo en Tapachula, Chiapas, tésis de maestria dir. Carolina Rivera Farfán, CIESAS Sureste.

Rojas Wiesner, Martha Luz y Angeles Cruz, Hugo (2000): "Migración femenina internacional en la frontera sur de México", en Papeles de población, núm. 23, Toluca: Universidad Autónoma del Estado de México.

Rojas Wiesner, Martha Luz (2007), "Mujeres y migración en la frontera sur de México", en Amérique Latine, Histoire et Mémoire, núm. 14, http:// alhim.revues.org/index2252.html, [7 de junio de 2010]

Ruiz, Olivia (2003): La migración centroamericana en la frontera sur, un perfil de riesgo en la migración internacional indocumentada, El Colegio de la Frontera Norte-Center for US/Mexican Studies(UCSD), San Diego, http:// repositories.cdlib.org/usmex/ruiz, [7 de junio de 2009].

Simon, Gildas (2008), La planète migratoire dans la mondialisation, Paris: Armand Colin.

Staut y Vera (2006), "Mujeres, políticas públicas y política: los caminos globales de Ciudad Juárez, Chihuahua-El Paso", en Regióny sociedad, núm. 37.

Swanger, Johanna (2007), "Feminist Community Building in la Ciudad Juarez: A Local Cultural Alternative to the structural Violence of Globalization", en Latin American Perspectives, vol. 34, núm. 108, Sage Publications.

\section{Fuentes hemerográficas}

Cordero, Flor; Pérez, Fredy M. (2009), "Se enfrentan policías y zetas en Frontera Comalapa”, en Cuarto 
Poder, 8 de julio, se desconoce el número y la página, http://noticias.cuarto-poder.com.mx/4p_apps/ periodico/pag.php?NzM5NzY\%3D, [7 de julio de 2010].

El Boletín (2010), "Evangelina Agrueta, de la Central General de Trabajadores, habla de su vida como dirigente sindical", vol. 15, núm.l, abril de 2010, p. 4, Se desconoce al autor. Publicado en línea http:// es.maquilasolidarity.org/node/817?SESS53bl7d9f47af lfod3lf6f3983a2605df=bywupbzrirje, [9 de diciembre 2010].

Gargallo, Francesca (2005), "El feminicidio en las repúblicas maquiladoras", en La Jornada, 17 de julio de 2005, se desconoce el número y la página. La traducción francesa fue publicada en línea http://risal. collectifs.net/spip.php?articlel541, [9 de diciembre de 2010].

La Prensa de Honduras (2008), "Cancilleria ya sabe como trabajamos" en La Prensa de Honduras, 9 de agosto 2008, se desconoce el autor, el número y la página, http:// archivo.laprensa.hn/ez/index.php/laprensa_user/ hondurenos/cancilleria_ya_sabe_como_trabajamos, [7 de julio de 2010].

La Prensa de Honduras (2009), "Hondureños a Japón para sacar pasaporte", en La Prensa de Honduras, 16 de marzo, se desconoce el autor, el número y la página, http://www.laprensa.hn/content/view/full/157205, [7 de julio de 2010]. 